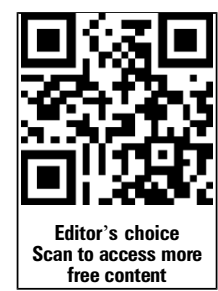

${ }^{1}$ Department of Sports Medicine, Oslo Sports Trauma Research Center, Norwegian School of Sport Sciences, Oslo, Norway

${ }^{2}$ Department of Orthopaedics, Oslo University Hospital, Oslo, Norway

${ }^{3}$ University of Oslo, Oslo, Norway

Correspondence to Bjørnar Haaland, Department of Sports Medicine, Oslo Sports Trauma Research Center, Norwegian School of Sport Sciences, PB 4014 Ullevål Stadion, Oslo 0806, Norway; bmhaaland@gmail.com

Accepted 19 October 2015 Published Online First 11 November 2015

\title{
Injury rate and injury patterns in FIS World Cup Alpine skiing (2006-2015): have the new ski regulations made an impact?
}

\author{
Bjørnar Haaland, ${ }^{1}$ Sophie E Steenstrup, ${ }^{1}$ Tone Bere, ${ }^{2}$ Roald Bahr, ${ }^{1}$ \\ Lars Nordsletten ${ }^{1,2,3}$
}

ABSTRACT

Background New regulations for ski equipment were implemented prior to the 2012/2013 season in the International Ski Federation (FIS) Alpine World Cup (WC). Objective To investigate the effect of the new ski regulations on the rate and pattern of injuries by comparing data before (2006-2012) and after the implementation (2012-2015).

Methods Injuries were recorded on the basis of the FIS Injury Surveillance System (FIS ISS) through retrospective interviews at the end of each of the nine WC seasons. All acute injuries that required medical attention were registered. Exposure was calculated on the basis of the official result lists.

Results The absolute injury rate (injuries/100 athletes/ season) was lower in the three seasons after the new ski regulations compared with the six seasons before (risk ratio (RR) $0.74,95 \% \mathrm{Cl} 0.63$ to 0.87 ). This was also the case for the relative injury rate (injuries/1000 runs) (RR $0.76,95 \% \mathrm{Cl} 0.59$ to 0.98$)$. These changes were evident for male skiers, not for female skiers. There was a lower absolute injury rate for upper body injuries (RR $0.56,95 \% \mathrm{Cl} 0.43$ to 0.77 ), while no difference was found for lower extremity injuries (RR 0.84, 95\% Cl 0.70 to 1.01).

Conclusions We found a lower rate of injuries in the three seasons after the new ski regulation compared with the six seasons before. However, the ability to draw conclusions on the effects of the equipment change in subgroups of sex, discipline or body part is restricted by the limited statistical power.

\section{INTRODUCTION}

The International Ski Federation (FIS) Alpine Ski World Cup (WC) is the top international circuit of Alpine skiing competitions. Alpine ski racing is a sport with high speed, spectacular jumps and intense turns. One-third of WC ski racers experience an acute injury during the 5-month winter season, and the knee is the most commonly injured body part with ACL injuries as the most frequent specific diagnosis. ${ }^{12}$ It is suggested that the injury risk is linked to increased skiing speed and turning forces. ${ }^{3}$

For injury prevention, understanding the injury mechanisms and the situations leading to injury is essential. $^{4}$ Both intrinsic factors and extrinsic factors, such as course setting and equipment, should be considered. ${ }^{4} 5$ The Alpine ski racing equipment varies between disciplines and sex. ${ }^{6}$ In the speed disciplines, downhill (DH) and super-G
(SG), long and straight skis are favourable, giving more stability at high speed. ${ }^{7}$ In the technical disciplines, giant slalom (GS) and slalom (SL), skiers have to carve tighter turns ${ }^{8}$; thus, the ski waist width, on-edge angle and ski flexion/stiffness are critical factors. ${ }^{9}$ Over the past decades, Alpine skis have been through significant changes in terms of length, width and sidecut radius, especially with the introduction of the carving skis (the hourglassshaped look). ${ }^{10}$ In relation to these equipment changes, an increased rate of severe knee injuries has been reported, suggesting that carving skis contribute to an increased risk of ACL injuries in particular. ${ }^{11} 12$

The regulations for WC racing skis were changed prior to the 2012/2013 season in an attempt by FIS to reduce the risk of injuries in WC Alpine skiing. ${ }^{13}$ The sidecut radius and ski length were increased for all disciplines except SL, making the skis longer, straighter and less aggressive. The most prominent change was made for GS, where the sidecut radius changed from 27 and $23 \mathrm{~m}$ to 35 and $30 \mathrm{~m}$ for males and females, respectively. ${ }^{6} 14$ The objective of this study was therefore to investigate the effect of the new ski regulations on the rate and pattern of injuries by comparing data before (2006-2012) and after (2012-2015) their implementation.

\section{MATERIALS AND METHODS}

\section{Study design and study population}

We recorded injuries in the FIS Injury Surveillance System (FIS ISS) ${ }^{1}{ }^{15}$ through retrospective interviews at one of the season-ending events in each of nine WC seasons (2006-2015). Data from the three recent seasons with the new ski regulations (2012-2015) were compared with data from the previous seasons (2006-2012). We defined the WC seasons as starting at the first events in Sölden (Austria) in October and lasting until the WC finals in March. Athletes, identified from the official FIS website, had to have started in at least one WC or World Ski Championship (WSC) event throughout the season to be included in this study. In addition, the athletes had to be identified by the head coach as an official member of the WC team. Athletes who were defined by the coaches as European Cup (EC) athletes, and therefore not a part of the WC team, were excluded. 


\section{Injury registration and athlete interviews}

All interviews were conducted in person by physicians or physiotherapists from the Oslo Sport Trauma Research Center (OSTRC) in the finishing area or during organised meetings at the competitor's hotels or race office. A standardised interview form was used, outlined as the week-by-week calendar of the Alpine WC, with the aim of facilitating athlete recall. If the athlete reported an injury, a specific injury form was completed, including information concerning: (1) injury location (expressed as the body part injured), (2) injured side, (3) injury severity (expressed as number of days of absence from full participation in training and competition), (4) injury type, (5) injury circumstance and (6) specific diagnosis. If the athlete was not present in person (due to injury or other reasons), we interviewed their coach, physician or physiotherapist.

The definition of injury as well as the classification of the type of injury and body part injured is based on the consensus statement on injury surveillance in football. ${ }^{16}$ An injury is defined as 'all acute injuries that occurred during training or competition and required attention by medical personnel'. ${ }^{16}$ Training included official training, team training and other activity on snow, for example, free skiing or warm up.

\section{Exposure registration}

To calculate exposure, we manually counted the number of started runs during the WC, WSC and Olympic Winter Games (OWG) competitions for each athlete per competition. If an athlete did not finish (DNF) or was disqualified from a run, we included the runs up to, as well as the run where the athlete DNF or was disqualified. This information was obtained from the official FIS website (http://www.fis-ski.com/alpine-skiing). The race calendar for each season was downloaded to identify the WC, WSC and OWG competitions. We summed the number of runs for each athlete per competition, per year and for the nine seasons.

\section{Statistical analysis}

The injury incidence was expressed as the absolute injury rate (number of injuries per 100 athletes per season) and the relative injury rate (number of injuries per 1000 competition runs). The calculations were based on the Poisson model, and we used Z-tests for comparing injury incidences between seasons. We computed risk ratio (RR) to compare the seasons before and after the change of ski regulations, with regard to body part injured and the different disciplines. All calculations were presented with $95 \%$ CIs. A two-tailed p level of $<0.05$ was considered statistically significant.

\section{RESULTS}

\section{Athlete interviews and injuries}

During the nine seasons (2006-2015), 2402 athlete interviews (1058 females and 1344 males) were conducted: 35\% were conducted with the athlete in person and $65 \%$ with the head coach or medical personnel. In total, 794 injuries (314 among females and 480 among males) were reported (table 1). Of these, 663 (84\%) were time-loss injuries (absence $\geq 1$ day) and 309 (39\%) were severe injuries (absence $>28$ days).

In total, $45 \%(n=354)$ of the injuries occurred during the WC/WSC/OWG competitions, 17\% $(n=133)$ during official training to these competitions, and $10 \%(n=80)$ happened during other FIS official training or competitions (table 1). Furthermore, 29\% $(n=227)$ of the injuries occurred in individual or team training on snow.

There were in total 5759 runs where the athlete DNF during the nine seasons. The rate of DNF was lower in the seasons after the new ski regulations (135, 95\% CI 128 to 141 per 1000 runs) compared with the seasons before (144, 95\% CI 140 to 148 ; RR; 0.94 , $95 \%$ CI 0.89 to 0.99 ) (table 1 ).

\section{Injury incidence}

In total, the absolute injury rate was 33.1 (95\% CI 30.8 to 35.4) injuries per 100 athletes per season. The absolute injury

Table 1 The number of athlete interviews, injuries, uncompleted runs and severity of injuries reported during nine seasons (2006-2015) in WC Alpine skiing

\begin{tabular}{|c|c|c|c|c|c|c|c|c|c|c|}
\hline & \multicolumn{10}{|l|}{ Seasons } \\
\hline & $06 / 07$ & $07 / 08$ & $08 / 09$ & 09/10 & $10 / 11$ & $11 / 12$ & $12 / 13$ & $13 / 14$ & $14 / 15$ & Total \\
\hline \multicolumn{11}{|l|}{ Interviews } \\
\hline Male & 144 & 148 & 148 & 140 & 157 & 148 & 163 & 149 & 147 & 1344 \\
\hline Female & 116 & 113 & 115 & 128 & 118 & 118 & 124 & 119 & 107 & 1058 \\
\hline Total & 260 & 261 & 263 & 268 & 275 & 266 & 287 & 268 & 254 & 2402 \\
\hline \multicolumn{11}{|l|}{ Injuries (\%) } \\
\hline WC/WSC/OWG & $36(43)$ & $51(49)$ & $32(37)$ & $43(47)$ & $58(46)$ & $41(49)$ & $27(36)$ & $27(46)$ & $39(48)$ & $354(45)$ \\
\hline Official training to WC/WSC/OWG & $11(13)$ & $19(18)$ & $19(22)$ & $21(23)$ & $18(14)$ & $13(15)$ & $12(16)$ & $8(14)$ & $12(15)$ & $133(17)$ \\
\hline Other FIS/other competitions & $13(15)$ & $10(10)$ & $4(5)$ & $3(3)$ & $11(9)$ & $6(7)$ & $11(14)$ & $8(14)$ & $4(5)$ & $70(9)$ \\
\hline Official FIS training & $0(0)$ & $1(1)$ & $3(3)$ & $1(1)$ & $2(2)$ & $0(0)$ & $0(0)$ & $2(3)$ & $1(1)$ & $10(1)$ \\
\hline Other training activity on snow & $24(29)$ & $24(23)$ & $29(33)$ & $23(25)$ & $37(29)$ & $24(29)$ & $26(34)$ & $14(24)$ & $26(32)$ & $227(29)$ \\
\hline Total & $84(100)$ & $105(100)$ & $87(100)$ & $91(100)$ & $126(100)$ & $84(100)$ & $76(100)$ & $59(100)$ & $82(100)$ & $794(100)$ \\
\hline \multicolumn{11}{|l|}{ Severe injuries (\%) } \\
\hline Overall (>28 days) & $31(37)$ & $28(27)$ & $36(41)$ & $41(45)$ & $46(37)$ & $25(30)$ & $37(49)$ & $28(47)$ & $37(45)$ & 309 (39) \\
\hline WC/WSC/OWG (>28 days) & $11(31)$ & $15(29)$ & $10(31)$ & $17(40)$ & $18(31)$ & $11(27)$ & $11(41)$ & $13(48)$ & $15(38)$ & $121(34)$ \\
\hline \multicolumn{11}{|l|}{ Time-loss injuries (\%) } \\
\hline Overall (>1 day absence) & $75(89)$ & $80(76)$ & $66(76)$ & $83(91)$ & $103(82)$ & $66(79)$ & $69(91)$ & $56(95)$ & $65(79)$ & $663(84)$ \\
\hline WC/WSC/OWG (>1 day absence) & $30(83)$ & $38(79)$ & $21(66)$ & $38(88)$ & $44(76)$ & $32(78)$ & $22(82)$ & $24(89)$ & $27(68)$ & $276(78)$ \\
\hline \multicolumn{11}{|l|}{ Uncompleted runs } \\
\hline DNF WC/WSC/OWG & 652 & 639 & 742 & 675 & 630 & 619 & 627 & 606 & 569 & 5759 \\
\hline
\end{tabular}

DNF, did not finish; FIS, The International Ski Federation; Overall, injuries in training and competition; WC/WSC/OWG, World Cup/World Ski Championships/Olympic Winter Games. 
rate was lower in the three seasons after the new ski regulations (26.8 injuries per 100 athletes per season, 95\% CI 23.3 to 30.4) compared with the six seasons before $(36.2$, 95\% CI 33.3 to 39.2; RR 0.74, 95\% CI 0.63 to 0.87 ) (figure 1 ). There was a lower rate of time-loss injuries ( $>1$ day absence) in the seasons after (23.5 injuries per 100 athletes per season, 95\% CI 20.1 to $26.8)$ compared to the seasons before $(29.7,95 \%$ CI 27.0 to 32.4; RR 0.79 , 95\% CI 0.67 to 0.94 ).

The 2402 athletes entered a total of 40873 runs in the WC/ OWG/WSC competitions during the nine seasons (2006-2015), including all disciplines (figure 1). The relative injury rate (injuries per 1000 runs) was lower in the three seasons after the change of regulations $(6.9,95 \%$ CI 5.5 to 8.4$)$ compared with the six seasons before $(9.5,95 \%$ CI 8.3 to 10.6 ; RR $0.73,95 \%$ CI 0.58 to 0.93 ) (figure 1 ). When including only the disciplines affected by the equipment change (DH, SG and GS), there was still a lower rate of injury after the new regulations (9.6 injuries per 1000 runs, 95\% CI 7.5 to 11.7$)$ compared to before (12.6, $95 \%$ CI 10.9 to 14.3 ; RR 0.76 , 95\% CI 0.59 to 0.98$)$. The discipline-specific injury rates are shown in table 2 .

Although the absolute injury rate was lower for male athletes after the new regulations, we did not detect a significant change for female skiers (table 3). Also, the relative injury rate per 1000 runs for males was lower in the seasons after compared to before, while no significant change was detected for females (table 3).

Lower body injuries (injuries below the waist) accounted for $68 \%$ of all injuries $(n=551)$ and injuries to the upper body accounted for $32 \%(n=257)$ during the nine seasons. Although there was a significantly lower absolute injury rate for upper body injuries after the new ski regulations $(6.9,95 \%$ CI 5.1 to 8.7) compared to before $(12.4,95 \%$ CI 10.7 to 14.2 ; RR 0.56 , $95 \%$ CI 0.41 to 0.75 ), we did not detect a difference for lower body injuries after the new regulations $(19.9$, 95\% CI 16.8 to
23.0) compared to before $(23.8$, 95\% CI 21.4 to 26.2 ; RR $0.84,95 \%$ CI 0.70 to 1.01$)$.

There was no difference in the knee injury rate per 100 athletes per season (RR 0.84 , 95\% CI 0.59 to 1.20 ) or per 1000 runs (RR $0.88,95 \%$ CI 0.69 to 1.11 ) after the new regulations (figure 2), nor was there a difference in the rate of ACL injuries (RR $0.77,95 \%$ CI 0.43 to 1.39 ), head/face or lower back injuries. However, for hand/finger/thumb injuries, there was a lower rate of injuries per 100 athletes in the seasons after $(2.2,95 \%$ CI 1.20 to 3.25$)$ compared to before $(4.1,95 \%$ CI 3.09 to 5.07; RR 0.55, 95\% CI 0.32 to 0.92 ). Also, for ankle/foot injuries, there was a lower rate of injuries after $(2.1,95 \%$ CI 1.41 to 2.85 ) compared to before $(0.9,95 \%$ CI 0.22 to 1.51 ; RR 0.41 , $95 \%$ CI 0.18 to 0.91 ).

\section{DISCUSSION}

This is the first study comparing the rate and pattern of injury before and after the implementation of new regulations for ski equipment in WC Alpine skiing. Our main finding was that the absolute injury rate, a measure of the overall injury risk during the competitive season, was $26 \%$ lower and the relative injury rate, a measure of injury risk during competition in the disciplines affected by the new regulations, was $24 \%$ lower in the three seasons after the equipment change compared with the six seasons before.

\section{Methodological considerations}

However, there are limitations to the study design that need to be considered when interpreting the results. First, the study population was limited to the world's top Alpine skiers. Therefore, although the RR comparing before with after the introduction of new ski regulations was reasonably consistent across subgroups, our ability to draw conclusions on the effects of the equipment change in subgroups of sex, discipline or body part is restricted by the limited statistical power. Second, we
Figure 1 Injury incidences in World Cup Alpine skiing during nine seasons (2006-2015), expressed as absolute injury rate (injuries per 100 athletes/ season) and relative injury rate (injuries per 1000 runs) for all disciplines computed with $95 \% \mathrm{Cl}$ for the specific seasons. The dashed line indicates the time period before (2006-2012) and after (2012-2015) the implementation of the ski changes.

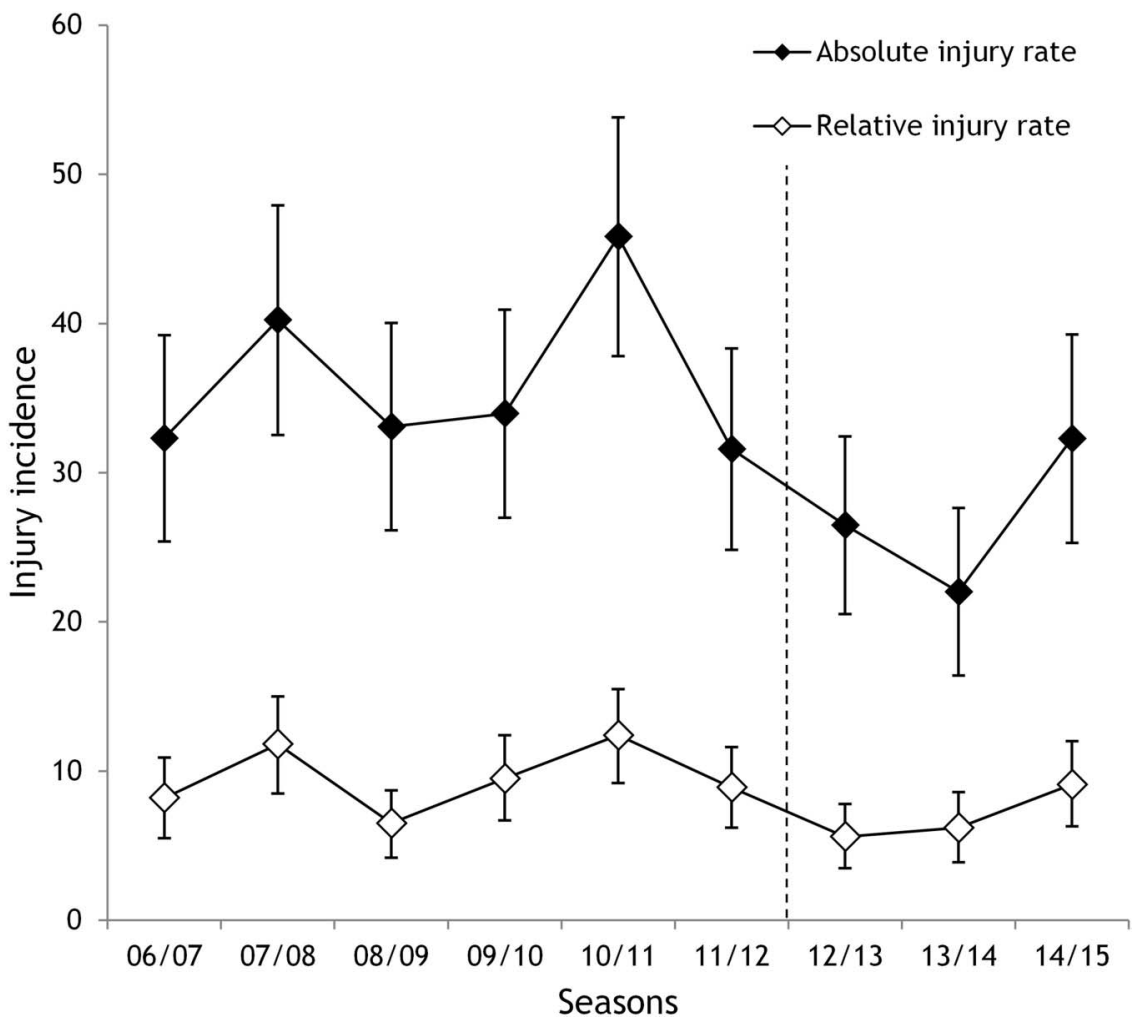


Table 2 Number of injuries and runs for each discipline during the six seasons before (2006-2012) and three seasons after (2012-2015) the change of ski regulations with relative injury rate (injuries per 1000 runs) and risk ratio computed with $95 \% \mathrm{Cl}$

\begin{tabular}{|c|c|c|c|c|c|c|c|}
\hline \multirow[b]{2}{*}{ Discipline } & \multicolumn{2}{|l|}{ Injuries (n) } & \multicolumn{2}{|c|}{ Exposure (runs) } & \multicolumn{2}{|l|}{ Incidence } & \multirow[b]{2}{*}{ RR $(95 \%$ Cl) } \\
\hline & 2006-2012 & 2012-2015 & 2006-2012 & 2012-2015 & 2006-2012 & 2012-2015 & \\
\hline Downhill & 113 & 37 & 6241 & 2782 & 18.1 (14.8 to 21.4$)$ & 13.3 (9.0 to 17.6$)$ & 0.74 (0.51 to 1.07$)$ \\
\hline Super-G & 49 & 21 & 4399 & 2022 & 11.1 (8.0 to 14.3$)$ & $10.4(5.9$ to 14.8$)$ & 0.93 (0.56 to 1.56$)$ \\
\hline Giant slalom & 59 & 25 & 6903 & 3852 & 8.5 (6.4 to 10.7$)$ & 6.5 (3.9 to 9.0 ) & $0.76(0.48$ to 1.21$)$ \\
\hline Slalom* & 40 & 10 & 9946 & 4728 & 4.0 (2.8 to 5.3 ) & 2.1 (0.8 to 3.4 ) & $0.53(0.26$ to 1.05$)$ \\
\hline Total & 261 & 93 & 27489 & 13384 & 9.5 (8.3 to 10.6$)$ & 6.9 (5.5 to 8.4$)$ & $0.73(0.58$ to 0.93$) \dagger$ \\
\hline
\end{tabular}

*Slalom did not undergo ski changes.

tSignificant difference $(p<0.05)$.

cannot rule out other factors, as the lower overall rate of injuries after the new ski regulations could possibly be due to the effect of variables not assessed by this study. Boots, bindings, course setting and snow conditions, along with a variety of intrinsic factors, such as experience, skier behaviour, technique, specialisation, physical and psychological factors, need to be considered. However, although the general focus on injuries has increased within FIS in recent years, the only other systematic change we are aware of during the observation period is the introduction of a new helmet standard prior to the 2013-2014 season. However, a strength of this study is that all athletes included were exposed to the change in ski regulations, as they needed to comply with FIS rules in order to compete in the WC.

Another limitation is that we recorded injuries only during the WC seasons, and therefore we cannot assess whether the equipment change had the same favourable effect during the off-season, when much of the training takes place on snow. Also, since the injury database is anonymised each year for confidentiality reasons, we cannot assess the effect of previous injury on injury risk. Previous injury is one of the the main risk factors for injury across body regions, injury types and sports. ${ }^{17-20}$ However, it seems unlikely that the rate of re-injuries would change from before to after the new ski regulations. Finally, during the nine WC seasons, we recorded injuries through interviews with athletes, coaches or team medical personnel at the end of each season. One-third of the interviews were performed with the athletes, while two-thirds were performed with the coach or medical personnel. The reason for this was that not all athletes were present at the WC finals, as only the athletes ranked among the top 30 in each discipline were qualified. Furthermore, when using retrospective interviews, recall bias may be a challenge. However, a methodological study considered retrospective athlete/coach interviews to be the best method to detect injuries during the season, ${ }^{15}$ and there is no reason to believe that recall bias has changed from before to after the ski changes.

\section{Injury incidence}

One likely reason for the reduction in injury rate is a reduction in falls, as measured by the proportion completing their run. There was a 6\% lower rate of DNF per 1000 runs in the seasons after compared with before the ski equipment change. We found that there was a $44 \%$ lower risk of injuries to the upper body in the seasons after the new ski regulations compared to before. Since upper body injuries typically occur as a result of falls and crashes, ${ }^{21}$ one reason for the lower rate of these injuries could be that the lower rate of DNF was caused by less falls. However, from our data, we cannot tell if an athlete who DNF fell or crashed or simply skied out of the course.

The reduction in injury rate was only evident among male athletes. One reason could be the low statistical power among female skiers, as discussed above. Another reason could be the sex-specific differences in the ski equipment, ${ }^{6}$ where the equipment changes made for male skiers may have had a larger impact on the risk of injury. However, it is not known whether the apparent difference in the effect on injury rate between males and females is related to the longer and less aggressive skis used by males, better technical and tactical adaptation by male skiers, or if it is course related. Since males have longer courses and therefore spend more time on the course, the risk reduction may be more evident.

Table 3 Sex distribution of injuries and runs during the six seasons before (2006-2012) and the three seasons after (2012-2015) the change of ski regulations with absolute injury rate (injuries per 100 athletes/season) and relative injury rate (injuries per 1000 runs) and risk ratio (RR) computed with $95 \% \mathrm{Cl}$

\begin{tabular}{|c|c|c|c|c|c|c|c|}
\hline & \multicolumn{2}{|l|}{ Injuries (n) } & \multicolumn{2}{|c|}{ Interviews/exposure } & \multicolumn{2}{|l|}{ Incidence } & \multirow[b]{2}{*}{ RR $(95 \% \mathrm{Cl})$} \\
\hline & 2006-2012 & 2012-2015 & 2006-2012 & 2012-2015 & 2006-2012 & 2012-2015 & \\
\hline \multicolumn{8}{|c|}{ Absolute injury rate (injuries per 100 athletes/season) } \\
\hline Male & 351 & 129 & 885 & 459 & 39.7 (35.5 to 43.8$)$ & 28.1 (23.3 to 33.0$)$ & $0.71(0.58 \text { to } 0.87)^{*}$ \\
\hline Female & 226 & 88 & 708 & 350 & $31.9(27.8$ to 36.1$)$ & 25.1 (19.9 to 30.4$)$ & $0.79(0.62$ to 1.01$)$ \\
\hline \multicolumn{8}{|c|}{ Relative injury rate (injuries per 1000 runs) } \\
\hline Male & 167 & 52 & 14618 & 6881 & $11.4(9.7$ to 13.2$)$ & 7.6 (5.5 to 9.6$)$ & $0.66(0.49 \text { to } 0.90)^{*}$ \\
\hline Female & 94 & 41 & 12871 & 6503 & $7.3(5.8$ to 8.8$)$ & $6.3(4.4$ to 8.2$)$ & $0.86(0.60$ to 1.25$)$ \\
\hline
\end{tabular}

${ }^{*}$ Significant difference $(p<0.05)$. 
Figure 2 Injury incidence, expressed as injuries per 100 athletes/season, for the different body parts before the (2006/2012) versus the seasons after (2012/2015). new equipment regulations

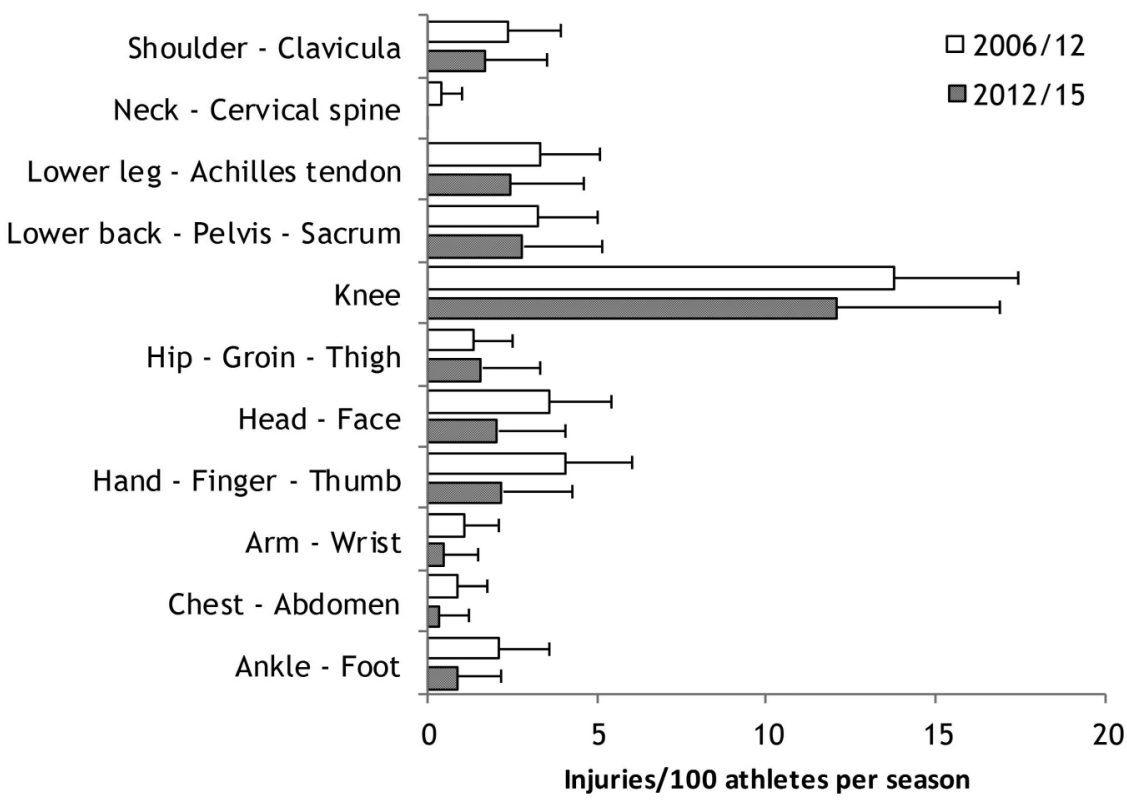

The equipment change may have led to changes in skiing technique as the aim of the new ski regulations was to reduce the aggressiveness of the ski-snow interaction, leading to a reduction in turning speed and forces. ${ }^{13}$ With a decreased selfsteering behaviour of the skis and possibly different turning techniques, course settings could also have changed after the new regulations. However, we have not investigated whether the courses are set differently after the new ski regulations in order to control speed or turn radii.

\section{Injury pattern}

As expected, knee injuries were the most common injury type during the nine seasons. No difference was found in the rate of knee injuries in general, or ACL injuries in particular, after the new regulations compared to before. However, as discussed above, low study power should be considered when interpreting these findings. To detect a significant difference, we would need to see considerably more ACL injuries, or increase the observation period, covering more seasons. Furthermore, we found no difference in the rate of severe injuries ( $>28$ days absence), but there was a lower rate of time-loss injuries ( $>1$ day absence) in the seasons after the new ski regulations.

The results from our study suggest that the new ski regulations have had an effect on the overall rate of injuries. Continued injury surveillance for more WC seasons will provide more data and allow us to ascertain the effect of the new ski regulations on the rate of knee and ACL injuries and the injury rate within subgroups of sex and disciplines.

\section{CONCLUSION}

We found a lower rate of injuries in the three seasons after the new ski regulation compared with the six seasons before. On the basis of the number of finishers per run, this may have been

\section{How might it impact on clinical practice in the future?}

Continued research into the effects of new ski regulations on the rate of injuries within subgroups of sex, disciplines and body part is needed.

\section{What are the findings?}

- This is the first study of World Cup (WC) Alpine skiing that has reported a significant difference in the overall injury rate among male WC Alpine ski racers before and after the new regulations of ski equipment.

- The risk of time-loss injuries (>1 day absence) and upper body injuries was lower for both males and females after the new ski regulations.

- There was a lower rate of 'did not finish' (DNF) in the seasons after the new ski regulations compared to before.

caused by a reduction in falls. However, the ability to draw conclusions on the effects of the equipment change in subgroups of sex, discipline or body part is restricted by the limited statistical power.

Acknowledgements The authors would like to thank the World Cup athletes, coaches and medical team personnel who participated in this study and the International Ski Federation staff and officials for all practical support.

Contributors BH, SES, TB, RB and LN contributed to the study conception, design and methodology. BH and SES coordinated the study and managed the data collection. BH wrote the first draft of the paper. All the authors contributed to the final manuscript. BH and LN are the guarantors.

Funding The Oslo Sports Trauma Research Center has been established at the Norwegian School of Sport Sciences through generous grants from the Royal Norwegian Ministry of Culture, the South-Eastern Norway Regional Health Authority, the International Olympic Committee, the Norwegian Olympic Committee \& Confederation of Sport, and Norsk Tipping AS. The FIS Injury Surveillance System is supported by the International Ski Federation and was established through a generous grant from DJO.

Competing interests None declared.

Ethics approval The project has been reviewed by the Regional Committee for Medical Research Ethics, South Eastern Norway Regional Health Authority, Norway and approved by the Social Science Data Services.

Provenance and peer review Not commissioned; externally peer reviewed.

\section{REFERENCES}

1 Bere T, Flørenes TW, Nordsletten L, et al. Sex differences in the risk of injury in World Cup alpine skiers: a 6-year cohort study. Br J Sports Med 2014;48:36-40. 


\section{Original article}

2 Flørenes TW, Bere T, Nordsletten L, et al. Injuries among male and female World Cup alpine skiers. Br J Sports Med 2009;43:973-8.

3 Gilgien M, Spörri J, Kröll J, et al. Mechanics of turning and jumping and skier speed are associated with injury risk in men's World Cup alpine skiing: a comparison between the competition disciplines. Br I Sports Med 2014:48:742-7.

4 Bahr R, Krosshaug T. Understanding injury mechanisms: a key component of preventing injuries in sport. Br I Sports Med 2005;39:324-9.

5 Krosshaug T, Andersen TE, Olsen OE, et al. Research approaches to describe the mechanisms of injuries in sport: limitations and possibilities. Br I Sports Med 2005:39:330-9.

6 FIS. International Ski Federation 2013. Specifications for competition equipment and commercial markings. Edition 2013/2014 (September 2013).

7 Spörri J, Kröll J, Amesberger G, et al. Perceived key injury risk factors in World Cup alpine ski racing —an explorative qualitative study with expert stakeholders. Br J Sports Med 2012;46:1059-64.

8 Lemaster R. Ultimate skiing. Human Kinetics, 2010.

9 Müller E, Schwameder H. Biomechanical aspects of new techniques in alpine skiing and ski-jumping. J Sports Sci 2003;21:679-92.

10 Masia S. Evolution of ski shape. J Int Skiing History Assoc 2005;17:33-7.

11 Johnson RJ, Ettlinger CF, Shealy JE. Update on injury trends in alpine skiing. In: Johnson RJ, Zucco P, Shealy JE, eds. Skiing trauma and Safety. West Conshohocken, PA: American Society for Testing and Materials, 2000: 108-18.
12 Johnson RJ, Natri A, Ettlinger $C F$, et al. Three-year study of carving skis. In: Müller E, ed. 2nd International Congress on skiing and science St. Christoph a. Arlberg, Austria: Verlag Dr. Kovac, 2001:529-43.

13 FIS. International Ski Federation 2011. Safety in Alpine Ski racing-status. University of Salzburg. http://www.fis-ski.com/mm/Document/document/General/04/22/03/ Feb22011Makingprogressforsafetyinskiracing_Neutral.pdf (accessed 24 Oct 2014).

14 FIS. International Ski Federation 2010. Specifications for competition equipment and commercial markings. Edition 2010/2011 (October 2010).

15 Flørenes TW, Nordsletten L, Heir S, et al. Recording injuries among World Cup skiers and snowboarders: a methodological study. Scand J Med Sci Sports 2011;21:196-205.

16 Fuller $\mathrm{CW}$, Ekstrand J, Junge $\mathrm{A}$, et al. Consensus statement on injury definitions and data collection procedures in studies of football (soccer) injuries. Br I Sports Med 2006:40:193-201.

17 Arnason A, Sigurdsson SB, Gudmundsson A, et al. Risk factors for injuries in football. Am J Sports Med 2004;32(1 Suppl):5S-16S.

18 Aroen A, Helgo D, Granlund OG, et al. Contralateral tendon rupture risk is increased in individuals with a previous Achilles tendon rupture. Scand J Med Sci Sports 2004;14:30-3.

19 Tate A, Turner GN, Knab SE, et al. Risk factors associated with shoulder pain and disability across the lifespan of competitive swimmers. J Athl Train 2012;47:149-58.

20 Bahr R, Bahr IA. Incidence of acute volleyball injuries: a prospective cohort study of injury mechanisms and risk factors. Scand J Med Sci Sports 1997;7:166-71.

21 Bere T, Flørenes TW, Krosshaug T, et al. A systematic video analysis of 69 injury cases in World Cup alpine skiing. Scand J Med Sci Sports 2014;24:667-77. 